\title{
Prevalence of Alzheimer dementia in Upper Egypt (desert areas)
}

Hamdy N. A. EL Tallawy ${ }^{1}$, Wafaa M. A. Farghaly', Mohamed Abd El Hamed ${ }^{1}$, Reda Badry ${ }^{1 *}$, Khaled Usama ${ }^{1}$, Ghaydaa A. Shehata', Amal M. Tohamy', Khaled O. Abdulghani², Mostafa K. Ghanem', Mohamed A. Sayed ${ }^{3}$, Ahmed H. Yousef ${ }^{1}$, Heba S. Hashem ${ }^{4}$ and Tarek A. Rageh ${ }^{1}$

\begin{abstract}
Background: Alzheimer's disease (AD) is the commonest type of Dementia worldwide. It rapidly increases with aging especially over 70 years.

Objectives: The aims of this study are to determine the prevalence of AD in Egyptian desert areas and to identify the risk factors and presenting symptoms.

Methods: This study was carried out on desert areas Al Kharga district and Al Quseir city. All population aged 50 years and more $(12,508)$ were included through door to door survey by seven Neuropsychiatrists. They were screened by standardized questionnaire prepared specifically. Positive cases were invited to attend Assiut Univ. Hospital where clinical evaluation, according to DSM-IV R. and necessary psychometric tests were applied.
\end{abstract}

Results: One hundred twenty-six patients with AD were diagnosed out of 12,508 people aged 50 years; yielding a prevalence of $1 \%$. Prevalence increases with age, from $0.34 \%$ for those aged $60 \leq 70$ years to $2.9 \%$ for subjects aged $70 \leq 80$ years, and $9.74 \%$ for those aged 80 years and more. AD is more common among females than males in all ages. Eighty-five percent of diagnosed patients are of mild and moderate degrees. Hypertension (14.3\%), smoking (10.3\%), diabetes (8.73\%), prior epilepsy (5.6\%), and family history of AD (3.5\%) are common risk factors. Impaired self-care (88.1\%), memory loss (84.1\%), impaired social judgment (77\%), agnosia (58.7\%), and behavioral changes (48.4\%) are the most frequently encountered symptoms of AD.

Conclusion: Prevalence of AD was 1\% for population aged 50 years and more, reaching 9.7 for patients aged $>80$ years. Early onset AD ( $<65$ years) was recorded in $7.9 \%$.

Keywords: Prevalence, Alzheimer's dementia, Desert, Egypt

\section{Introduction}

Alzheimer's disease (AD) is the most common type of dementia as it affects up to $75 \%$ of the 35 million people suffering from dementia in the world. It is a degenerative incurable progressive disease. It is mostly diagnosed in people over 65 years, but a less prevalent early onset form sometimes develops at earlier age group. The prevalence of Alzheimer's disease is doubled every 20 years [1].

A lot of data from European studies on the prevalence of $\mathrm{AD}$ stated that the age-standardized prevalence of $\mathrm{AD}$ in people aged 65 or more is $4.4 \%$ [1]. In a study

\footnotetext{
* Correspondence: redaalbadry02@gmail.com; redaalbadry@yahoo.com ${ }^{1}$ Department of Neurology and Psychiatry, Assuit University, Postbox: 71526 , Assiut, Egypt

Full list of author information is available at the end of the article
}

performed in the USA, a representative sample of persons over 70 years reported AD prevalence of 9.7\% [2]. The global prevalence of $\mathrm{AD}$ is estimated at $3.9 \%$ in people older than 60 years [3].

In developed countries, about one out of ten persons over 65 years of age suffers from dementia while in those older than 85 years, more than one-third have dementia $[4,5]$.

Comorbidities like hypertension, diabetes, smoking, dyslipidemia, and obesity have been found to potentially increase the risk of dementia. Moreover, cerebrovascular accidents, e.g., large cortical infarcts, multiple small infarcts, single strategically placed infarct, cortical changes owing to hypoperfusion, cerebral hemorrhage, vasculopathies, and white matter changes are generally precipitating factors to development of dementia [6, 7]. 
There are some non-cognitive behavioral and psychiatric disturbances usually found in patients with dementia, e.g., apathy, disinhibition, sleep disturbances, agitation, aggression, psychosis, and depression $[8,9]$.

The aims of this study are to determine the prevalence of Alzheimer Dementia in desert areas in Egypt and to identify the most common presenting symptoms and risk factors.

\section{Population and method}

This is a cross-sectional, door to door study, among population of Upper Egypt, (Desert areas). This study involved all the population aged 50 years and older, living in these areas for at least 6 months.

\section{Study areas}

This study was carried out in Al Kharga district, New valley Governorate and AL Quseir city, Red Sea Governorate. There are three large desert areas in Egypt; Western desert, Eastern desert, and Sinai Peninsula. Only $35,000 \mathrm{~km} 2-3.5 \%$ of the total land area is cultivated and permanently settled.

Most of the country lies within the wide band of desert that stretches eastwards from African's Atlantic coast across the continent and into Southeast Asia (https://en. wikipedia.org/wiki/Geography_of_Egypt).

The first studied area, Al Kharga district, New Valley Governorate is representative for western desert in Upper Egypt and the second area is AL Quseir city, Red Sea Governorate is a representative for Eastern desert in Upper Egypt.

We noticed some criteria about population of the desert areas, e.g., dietary habits depend on dry cereals, sheep meat, and dates. More over consanguineous marriage is very common among population of those areas and life expectancy is longer than that of urban areas.

\section{Method}

This study was carried out through two stages and every stage involved three phases. Stage one from January1st 2006 up to July 31st 2008 in Al Kharga district. Stage two from July 1st 2009 to Jan. 31st 2012 in Al Qusier city. Three phases for each of the two stages include:

Phase I: Screening phase, screening of all inhabitants (aged 50 years and more) was performed by seven specialists of Neuropsychiatry using standard Arabic Questionnaire [10], and modified Mini-Mental State Examination (MMSE), to pick up suspected cases. Phases 2: Diagnostic phase, all participants who were suspected to have dementia (MMSE $\leq 23$ or $\leq 21$ for illiterate subjects) were invited to attend General hospital in Al Kharga or Al Quseir for case ascertainment. All suspected dementia cases were subjected to a full neuropsychiatric assessment by nine staff members of Neurology (of Assiut University Hospital) separately, psychometeric assessment through DSM IV-R, Cognitive Abilities Screening Instrument (CASI), instrumental Activities of Daily Living Scale (ADSL), Geriatric Depression Scale (GDS) for diagnosis of depression, and Hachinski ischemic score $\leq 5$ indicate AD [11]. Staging of AD was done as follows: those having a score 17-21 on MMSE were considered to have mild dementia, 9-16 have moderate, and less than 9 have severe degree of dementia. Two points were added for each group in case of educated subjects [12]. Phase 3: investigatory phase; a battery of investigations, i.e., ECG, liver function test, kidney function test (blood urea and creatinine), complete blood picture, blood sugar curve, serum uric acid, thyroid function test (free T3, T4, TSH), and lipogram. CT and/or MRI of the brain were carried out for all patients.

Statistical analysis was carried out using SPSS version 16 to assess relations and comparisons.

\section{Results}

Prevalence of Alzheimer dementia (AD) was 1/1000 among population aged 50 years and more. It was slightly higher in $\mathrm{Al}$ Kharga district (1.03\%) than $\mathrm{Al}$ Quseir city (0.97\%), Table 1.

Prevalence of AD was higher among females (1.26\%) than males $(0.93 \%)$ in all age groups, Table 2.

Most cases of $\mathrm{AD}$ in this study are of moderate (43.7\%) and mild degrees (41.3\%). Severe degree of AD was higher in $\mathrm{Al}$ Quseir city (26.2\%) than $\mathrm{Al}$ Kharga district $(9.5 \%)$ (Table 3).

Table 4 reported the possible risk factors for $\mathrm{AD}$ in the studied areas.

Table 5 clarifies the order of frequency of symptoms by which $\mathrm{AD}$ patients commonly presented with.

It was recorded that $7.9 \%$ of total $\mathrm{AD}$ cases were of early onset dementia ( $<65$ year), and it was higher among males $(9.1 \%)$ than females (7\%). Late onset AD (>65 years) was recorded in $92.1 \%$ and was higher among females (93\%) than males (90.9\%). Behavioral changes were recorded among $30 \%$ of $\mathrm{AD}$ of early onset $\mathrm{AD}(<65$ year), while it was recorded in $50 \%$ of late onset $\mathrm{AD}$ ( $>65$ years).

\section{Discussion}

Alzheimer's disease is characterized by progressive cognitive disability usually beginning with impairment of recent memories, but finally affecting all intellectual functions [13].

Prevalence of $\mathrm{AD}$ widely differs worldwide and increases with aging especially after the age of 65 years. Its etiology is unknown, but different risk factors including genetic predisposition play a role in the development of 
Table 1 Age-specific prevalence of Alzheimer's dementia in upper Egypt, Desert area (Al Kharga and Al Quseir)

\begin{tabular}{|c|c|c|c|c|c|c|}
\hline \multirow[t]{2}{*}{ Age group } & \multicolumn{2}{|l|}{ Total } & \multicolumn{2}{|c|}{ Al Quseir city } & \multicolumn{2}{|c|}{ Al Kharga District } \\
\hline & $N$ & Prev. \% & $N$ & Prev. \% & $N$ & Prev. \% \\
\hline $50-<60$ years & $7 / 6458$ & 0.1 & $3 / 2222$ & 0.13 & $4 / 4236$ & 0.09 \\
\hline $60-<70$ years & $13 / 3765$ & 0.34 & $8 / 1411$ & 0.57 & $5 / 2354$ & 0.21 \\
\hline $70-<80$ years & $49 / 1700$ & 2.9 & 18/539 & 3.34 & $31 / 1161$ & 2.67 \\
\hline$\geq 80$ years & $57 / 585$ & 9.74 & $13 / 163$ & 7.97 & $44 / 422$ & 10.4 \\
\hline Total & $126 / 12508$ & 1 & $42 / 4335$ & 0.97 & $84 / 8173$ & 1.03 \\
\hline
\end{tabular}

the disease. The high frequency of consanguineous marriage and the high frequency of positive family history of $\mathrm{AD}$ in the studied areas, especially in $\mathrm{Al}$ Kharga district, may support this hypothesis.

This study revealed that the total prevalence of AD in the studied areas was $1 \%$ among population aged 50 years and more, reaching $2.9 \%$ at $70-<80$ years and $9.74 \%$ at 80 years and more. Prevalence rapidly increases after the age of 70 years in this study (8.5-fold) especially among Al-Kharga population (12-fold). It was found that prevalence of $\mathrm{AD}$ was higher in $\mathrm{Al}$ Quseir city than $\mathrm{Al}$ Kharga (nearly 2-fold) among all age groups (50 up to < 80 years). On the other hand, the reverse was observed after the age of 80 years. This could be explained by the higher number of centenarians among population in $\mathrm{Al}$ Kharga than $\mathrm{Al}$ Quseir city as well as the high rates of heavy metal pollution in $\mathrm{Al}$ Quseir city which might contribute to the higher prevalence rates among younger age groups. The role of heavy metal intoxication in development of degenerative diseases among populations in this study will be published later on as a separate entity. Similarly, [14] reported that the prevalence rates of AD also rise exponentially with age, increasing markedly after 65 years.

Harvey and colleagues [15] reported that the prevalence of dementia increases exponentially between 45 and 60 years of age. Alzheimer's disease is the most frequent diagnosis in early onset dementia followed by vascular dementia $(\mathrm{VaD})$ and fronto-temporal dementia (FTD). In this study, early onset $\mathrm{AD}(50 \sim \leq 65$ years) was recorded in $7.9 \%$ of all dementia cases, and was more common among men $(9.1 \%)$ than women $(7 \%)$. Behavioral changes were recorded among 30\% of early onset $\mathrm{AD}$ cases. $\mathrm{AD}$ of early onset $(50 \sim 65$ years) in this study was recorded among two brothers and one sister in one family and two brothers in another family in $\mathrm{Al}$ Kharga district.

Compared with other studies in Africa, Asia, the USA, and Europe, the prevalence was higher among African-American and Hispanic population living in the USA, but lower for Africans in their homelands, for reasons that remain unclear [16-18]. This different prevalence rates among different populations could be explained on the basis of different genetic susceptibility, different numbers of centenarians among various populations, and different methods of case ascertainment in different studies.

Prevalence of Alzheimer's dementia was higher among females than males in all age groups. Experimental studies in mice support the higher risk of females for $A D$ mediated by A $\beta$, APP, or both. The increased synaptic degeneration and altered inflammatory response may explain the increased AD risk in females [19].

Although [2] explained this gender difference in disease prevalence on the basis of the finding that women live longer than men, the finding of male to female ratio in our study (1353/932, i.e., 1.5:1) in the age group 70 years and more did not support this opinion. However, the biologic mechanisms underlying sex difference in both prevalence and severity are not fully understood [19]. The full impact of sex as a basic biologic variable on this neurodegenerative disease remains elusive. A lot of studies suggested that gender and age are the predominant risk factors for $\mathrm{AD}$ [20]. On the other hand, some studies, in the USA and other countries, assumed that age appears to consistently predict $\mathrm{AD}$ but gender results are inconsistent [21]. This discrepant sex prevalence and severity could be explained by the suggestion

Table 2 Age and sex-specific prevalence of Alzheimer's dementia in Upper Egypt, Desert areas (AL Kharga and AL Quseir)

\begin{tabular}{|c|c|c|c|c|c|c|}
\hline \multirow[t]{2}{*}{ Age group } & \multicolumn{2}{|l|}{ Total } & \multicolumn{2}{|l|}{ Male } & \multicolumn{2}{|l|}{ Females } \\
\hline & $\bar{N}$ & Prev. $\%$ & $\bar{N}$ & Prev. $\%$ & $\bar{N}$ & Prev. \% \\
\hline $50-<60$ years & $7 / 6458$ & 0.1 & $2 / 3404$ & 0.06 & $5 / 3054$ & 0.16 \\
\hline $60-<70$ years & $13 / 3765$ & 0.34 & $7 / 2131$ & 0.33 & $6 / 1634$ & 0.36 \\
\hline $70-<80$ years & 49/1700 & 2.9 & 20/1020 & 1.96 & $29 / 680$ & 4.26 \\
\hline 80 years $†$ & $57 / 585$ & 9.74 & $26 / 333$ & 7.8 & $31 / 252$ & 12.3 \\
\hline Total & $126 / 12508$ & 1 & $55 / 6888$ & 0.93 & $71 / 5620$ & 1.26 \\
\hline
\end{tabular}


Table 3 Degree of Alzheimer's dementia according to MMSE scores in Upper Egypt, Desert areas (AL Kharga and AL Quseir)

\begin{tabular}{|c|c|c|c|c|c|c|}
\hline \multirow[t]{2}{*}{ Degree } & \multicolumn{2}{|c|}{ Total } & \multicolumn{2}{|c|}{ Al Kharga District } & \multicolumn{2}{|c|}{ Al Quseir city } \\
\hline & $N$ & $\%$ & $N$ & $\%$ & $\bar{N}$ & $\%$ \\
\hline Mild & 52 & 41.3 & 39 & 46.4 & 13 & 31 \\
\hline Moderate & 55 & 43.7 & 37 & 44 & 18 & 42.8 \\
\hline Severe & 19 & 15 & 8 & 9.5 & 11 & 26.2 \\
\hline Total & 126 & 100 & 84 & 100 & 42 & 100 \\
\hline
\end{tabular}

that $\mathrm{AD}$ pathogenesis in women may be affected by metabolic changes induced by gonadal hormones, such as estrogen, which is known to have a protective effect on the brain. Loss of estrogen after menopause could partially lead to the deficits seen in brain metabolism in mild cognitive impairment (MCI) and AD [15].

About $85 \%$ of studied AD patients are of mild and moderate degrees in this study. This could be explained by the adopted epidemiological methods, door to door survey, where specialists of neurology reached patients at their homes. Using a standardized questionnaire and application of MMSE allows picking up mild and moderate cases. $\mathrm{AD}$ patients in these localities did not seek medical advice except in late stages or when behavioral changes are prominent. Most of the symptoms, especially memory deficits, in these localities are attributed to the aging process.

Presence of comorbidities, e.g., diabetes, hypertension, smoking, obesity, and dyslipidemia have all been found to increase the risk of $\mathrm{AD}[7,22]$. In this study, the most common reported risk factors are in order of frequency, hypertension, family history of dementia, smoking, diabetes mellitus, and epilepsy prior to $\mathrm{AD}$.

Fratiglioni and colleagues [23] stated that, based on epidemiological studies, neuroimaging methods, and neuropathology researches, three etiological hypotheses for the development of AD have been reported with moderate or strong evidences. These include genetic, vascular (hypertension, diabetes, smoking, obesity, and high total cholesterol levels) and psychosocial risk factors. The genetic factors appear more prominent in $\mathrm{Al}$ Kharga district study where there was a higher rate of positive family history of

Table 4 Prevalence of possible risk factors for Alzheimer's Dementia in Upper Egypt, Desert area, in order of Frequency

\begin{tabular}{|c|c|c|c|c|c|c|}
\hline \multirow[t]{2}{*}{ Risk factors } & \multicolumn{2}{|c|}{$\begin{array}{l}\text { Total } \\
N=126\end{array}$} & \multicolumn{2}{|c|}{$\begin{array}{l}\text { AD Al Kharga } \\
N=84\end{array}$} & \multicolumn{2}{|c|}{$\begin{array}{l}\text { Al Quseir } \\
N=42\end{array}$} \\
\hline & $N$ & $\%$ & $N$ & $\%$ & $N$ & $\%$ \\
\hline Hypertension & 18 & 14.3 & 7 & 8.3 & 11 & 26 \\
\hline Family history of dementia & 17 & 13.5 & 14 & 16.7 & 3 & 7.1 \\
\hline Smoking & 13 & 10.3 & 7 & 8.3 & 6 & 14.3 \\
\hline Diabetes mellitus & 11 & 8.73 & 3 & 3.6 & 8 & 19 \\
\hline Epilepsy prior to dementia & 7 & 5.6 & 3 & 3.6 & 4 & 9.5 \\
\hline
\end{tabular}

Table 5 Neuropsychiatric profiles of patients with Alzheimer's disease in upper Egypt, Desert areas (AL Kharga and AL Quseir)

\begin{tabular}{|c|c|c|c|c|c|c|}
\hline \multirow[t]{2}{*}{ Symptom } & \multicolumn{2}{|c|}{$\begin{array}{l}\text { AD patients } \\
\text { Total } \\
N=126\end{array}$} & \multicolumn{2}{|c|}{$\begin{array}{l}\text { AD patients } \\
\text { Al Kharga } \\
N=84\end{array}$} & \multicolumn{2}{|c|}{$\begin{array}{l}\text { AD patients } \\
\text { Al Quseir } \\
N=42\end{array}$} \\
\hline & $N$ & $\%$ & $N$ & $\%$ & $N$ & $\%$ \\
\hline Impaired self-care & 111 & 88.1 & 81 & 96.4 & 30 & 71.4 \\
\hline Memory loss & 106 & 84.1 & 72 & 85.7 & 34 & 81 \\
\hline Social judgment & 97 & 77 & 71 & 84.5 & 26 & 61.9 \\
\hline Agnosia & 74 & 58.7 & 60 & 71.4 & 14 & 33.3 \\
\hline Behavioral changes & 61 & 48.4 & 47 & 56 & 14 & 33.3 \\
\hline Personality changes & 57 & 45.2 & 44 & 52.4 & 13 & 31 \\
\hline Disorientation & 45 & 35.7 & 30 & 35.7 & 15 & 35.7 \\
\hline Apraxia & 35 & 27.8 & 23 & 27.4 & 12 & 28.6 \\
\hline Psychotic $^{a}$ symptoms & 31 & 24.6 & 19 & 22.6 & 12 & 28.6 \\
\hline Incontinence & 29 & 23 & 19 & 22.6 & 10 & 23.8 \\
\hline Language difficulty & 18 & 14.3 & 9 & 10.7 & 9 & 21.4 \\
\hline Gait difficulty & 16 & 12.7 & 8 & 9.5 & 8 & 19.1 \\
\hline
\end{tabular}

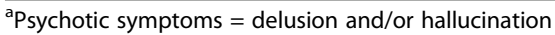

$\mathrm{AD}(13.5 \%)$ which was attributed to the high rate of consanguineous marriage $(>80 \%)$ in this closed locality. On the other hand, the vascular hypothesis is more prominent in $\mathrm{Al}$ Quseir study in the form of higher rate of hypertension, diabetes, and smoking.

During course of dementia, $80-90 \%$ of people with dementia had evidence of neuropsychiatric symptoms (Steinberg and colleagues 2004). Non-cognitive behavioral and psychiatric disturbances such as apathy, disinhibited behavior, and sleep disturbances are usually observed in people suffering from dementia [9]. Several studies assured that sleep disturbances were more frequent in patients with $\mathrm{AD}$, and the most common sleep behavior being a tendency to confusion in early evening and wandering at night [24]. Definite symptoms such as delusions and aberrant motor behavior $(\mathrm{ABM})$ were found more common in patients with $\mathrm{AD}$ than in those with vascular dementia [25].

This study clarified that impaired self-care, memory loss, impaired social judgment, agnosia, behavioral changes, personality changes, disorientation, apraxia, and psychotic symptoms are the most frequent features of the neuropsychiatric profile of $\mathrm{AD}$ patients (in order of frequency). The explanation of the differences of neuropsychiatric profile of $\mathrm{AD}$ in this study and other studies are related to the type of methodology where most of the studies are hospital-based studies, and most of the referred AD patients to the hospital are presented with behavioral changes.

Fischer [26] mentioned that delusions occur in approximately one-third of $\mathrm{AD}$, and $\mathrm{AD}$ with psychosis has an increased rate of cognitive decline. Hsieh and colleagues (2008) reported delusions in $23.1 \%$ of AD cases 
in nursing homes, and $28.0 \%$ of $\mathrm{AD}$ of outpatient department. In this study, psychotic symptoms (delusion and hallucination) were reported in about one-fourth of cases of $\mathrm{AD}(24.6 \%)$. These cases of $\mathrm{AD}$ having psychotic symptoms, especially positive symptoms (delusions, hallucinations, and agitation), seek early medical advice because of the stigma of these symptoms.

The study of neuropsychiatric profile of patients with dementia may have a role in differentiating different types of dementia from each other, and thus could have a role in planning treatment [27], particularly because such symptoms interfere with the quality of life of both patients and their care-givers.

\section{Acknowledgements}

Not applicable in this section.

\section{Funding}

There is no source of funding for the research.

\section{Availability of data and materials}

Data supporting the results of this article are included within the article.

\section{Authors' contributions}

HNAET, WMAF, MAEH, and RB carried out this work and wrote the manuscript. KOM, AMT, KOA, and MKG designed the study, had done the statistical analysis. MAS, AHY, HSH, and GAS did the literature search, and coordinated the research team. All authors were involved in drafting the article or revising it critically for important intellectual content, and all authors approved the final version to be published.

\section{Ethics approval and consent to participate}

A written consent was taken from all of the participants after explaining the details, benefits, as well as risks to them. The study was approved from the institutional ethics committee of Faculty of medicine, Assiut University under the number of (R0165N2016) at 16th of June, 2016

\section{Consent for publication}

Not applicable in this section.

\section{Competing interests}

The authors declare that they have no competing interests.

\section{Publisher's Note}

Springer Nature remains neutral with regard to jurisdictional claims in published maps and institutional affiliations.

\section{Author details}

'Department of Neurology and Psychiatry, Assuit University, Postbox: 71526 , Assiut, Egypt. ${ }^{2}$ Department of Neurology and Psychiatry, Helwan University School of Medicine, Helwan, Egypt. ${ }^{3}$ Department of Neurology and Psychiatry, Sohag University, Sohag, Egypt. ${ }^{4}$ National institute of Research, Cairo, Egypt.

Received: 7 September 2018 Accepted: 22 April 2019 Published online: 15 May 2019

\section{References}

1. Povova, Ambroz P, Bar M, Pavukova V, Sery O, Tomaskova H, Janout V. Epidemiological of and risk factors for Alzheimer's disease: a review. Biomed Pap Med Fac Palacky Univ Olomouc. 2012;156(2):108-14.

2. Plassman BL, Langa KM, Fischer GG, Heeringa SG, Weir DR, Ofstedal MB, Burke JR, Hurd MD, Potter GG, Rodgers WL, Steffens DC, Willis RJ, Wallace RB. Prevalence of dementia in the United States: the aging, demographics, and memory study. Neuroepidemiology. 2007;29:125-32.

3. Ferri CP, Prince M, Brayne C, Brodaty H, Fratiglioni L, Ganguli M, Hall K Hasegawa K, Hendrie H, Huang Y, Jorm A, Mathers C, Menezes PR, Rimmer
E, Scazufca M. Global prevalence of dementia: a Delphi consensus study. Lancet. 2005:366:2112-7.

4. Corrada MM, Brookmeyer R, Berlau D, Paganini- Hill A, Kawas CH. Prevalence of dementia after age 90: results from the 90+ study. Neurology. 2008;71: $337-43$.

5. Von Strauss E, Vitanen M, De Ronchi D, Winblad B, Fratiglioni L. Aging and the occurrence of dementia: findings from a population based cohort with a large sample of nonagenarians. Arch Neurol. 1999;56:587-92.

6. Reitz C, Bos MJ, Hofman A, Koudstaal PJ, Breteler MM. Prestroke cognitive performance, incident stroke, and risk of dementia: the Rotterdam study. Stroke. 2008:39:36-41.

7. Rastas S, Pirttila T, Mattila K, Verkkoniemi A, Juva K, Niinisto L, Lansimies E, Sulkava R. Vascular risk factors and dementia in the general population aged > 85 years: prospective population-based study. Neuribiol Aging. 2010;31:1-7.

8. Steinberg M, Tschanz JT, Corcoran C, et al. The persistence of neuropsychiatric symptoms in dementia: at the Cache County study. Int $J$ Geriatr Psychiatry. 2004:19:19-26.

9. Chung JA, Cummings JL. Neurobehavioral and neuropsychiatric symptoms in Alzheimer's disease: characteristics and treatment. Neurol Clin. 2000:18: $829-46$

10. El Tallawy HN, Farghaly WM, Metwaly NA, Rageh TA, Shehata GA, Elfetoh NA, Hegazy AM, El-Moselhy EA, Rayan I, Al-Fawal BM, Abd Elhamed MA. Door-to-door survey of major neurological disorders in Al Kharga District, New Valley, Egypt: methodological aspects. Neuroepidemiology. 2010;35(3): 185-90. https://doi.org/10.1159/000314345 E3pub 2010 Jul 24.

11. Hachinski VC, lliff LD, Zilhka E, Du Boulay GH, McAllister VL, Marshall J, Russell RW, Symon L. Cerebral blood flow in dementia. Arch Neurol. 1975; 32(9):632-7.

12. Farrag A, Farwiz HM, Khedr EH, Mahfouz RM, Omran SM. Prevalence of Alzheimer's disease and other dementing disorders: Assiut-Upper Egypt study. Dement Geriatr Cogn Disord. 1998;9(6):323-8.

13. Serrano-Pozo A, Frosch MP, Maslish E, Hyman BT. Neuropathologica alterations in Alzheimer disease. Cold Spring Harb Perspect Med. 2011 https://doi.org/10.1101/cshperspect. a006189

14. Evans DA, Funkenstein HH, Albert MS, Scherr PA, Cook NR, Chown MJ, Hebert LE, Hennekens CH, Taylor JO. Prevalence of Alzheimer's disease in a community population of older persons. Higher than previously repoted. JAMA. 1989:262:2551-6.

15. Carroll JC, Villamagna A, Pike CJ, Rosario ER. Continuous and cyclic progesterone differentially interact with estradiol in the regulation of Alzheimer-like pathology in female 3xTransgenic-Alzheimer's disease mice. Endocrinology. 2010;151(6):2713-22. https://doi.org/10.1210/en.2009-1487 Epub 2010 Apr 21.

16. Ogunniyi A, Baiyewu O, Gureje O, Hall KS, Univerzagt F, Siu S, Gao S, Farlow M, Oluwole OS, komolafe O, et al. Epidemiology of dementia in Nigeria: results from the Indianapolis-lbadan study. Eur J Neurol. 2000;7:485-90.

17. Unverzagt FW, Gao S, Baiyewu O, Ogunniyi AO, Gureje O, Perkins A, Emsley CL, Dickens J, Evans R, Musick B, Hall KS, Hui SL, Hendrie HC. Prevalence of cognitive impairment. Neurology. 2001;57(9):1655-62.

18. Olayinka OO, Mbuyi NN. Epidemiology of dementia among the elderly in Sub-Saharan Africa. Int J Alzheimers Dis. 2014:2014:195750.

19. Carter, Eileen M. Resnick, Monica Mallampalli and Anna Kalbarczk. Sex and gender differences in Alzheimer's disease: recommendations for future research. J Women Health, 2012;21(10). Dol: https://doi.org/10.1089/jwh. 2012.3789

20. Vifa J, Lloret A. Why women have more Alzheimer' disease than men: gender and mitochondrial toxicity of amyloid-beta peptide. J Alzheimers Dis. 2010;2(Suppi):S527-33.

21. Edland SD, Rocca WA, Petersen RC, et al. Dementia and Alzheimer disease incidence rates do not vary by sex in Rochester, Minn. Arch Neurol. 2002;59: 1589-93.

22. Harvey RJ, Skelton-Robinson M, Rossor MN. The prevalence and causes of dementia in people under the age of 65 years. J Neurosurg Psychatry. 2003; 74:1206-9.

23. Fratiglioni L, Von Strauss E, Qiu CX. Epidemiology of the dementias of old age. In: Dening T, Jacoby R, Oppenheimer C, Thomas A, editors. The Oxford textbook of old age psychiatry. 4th ed. New York: Oxford University Press; 2008. p. 391-406.

24. Grace JB, Walker MP, Mckeith IG. A comparison of sleep profiles in patients with dementia with Lewy bodies and Alzheimer's disease. Int J Geriatr Psychiatry. 2000;15:1028-33. 
25. Ikeda M, Fukuhara R, Shigenobu K, et al. Dementia associated mental and behavioral disturbances in elderly people in the community: findings from the first Nakayama study. J Neurol Neurosurg Psychiatry. 2004;75:146-8.

26. Jorm AF, Korten AE, Henderson AS. The prevalence of dementia: a quantitative integration of the literature. Acta Psychiatr Scand. 1987;76:465-79.

27. Alten $P$, de Vugt ME, Jaspers $N$, et al. The course of neuropsychiatric symptoms in dementia. Part II: relationships among behavioral subsyndromes and the influence of clinical variables. Int I Geriat Psychiatry. 2005:20:531-6.

Submit your manuscript to a SpringerOpen ${ }^{\mathcal{O}}$ journal and benefit from:

- Convenient online submission

- Rigorous peer review

- Open access: articles freely available online

High visibility within the field

- Retaining the copyright to your article

Submit your next manuscript at $\boldsymbol{\nabla}$ springeropen.com 